\title{
Assessment of Performance-based Requirements for Structural Design
}

KRISTIAN HERTZ

Department of Civil Engineering

Building 118, Technical University of Denmark

DK-2800, Kgs. Lyngby, Denmark

\section{ABSTRACT}

The paper presents how actions can be assessed for a performance-based structural fire safety design from the first formulations in the building program to the final derivations of the fire load to be applied for each structural member. In order to indicate what is of importance for the assessment of the requirements, a couple of simple analyses of structural response are made. The examples are chosen deliberately to show the difference between a traditional design based on standard fire resistance and a performance-based approach.

A methodology is developed for a decision on the safety level and for a detailed assessment of the requirements.

The design requirements to be used for a factory producing elements for industrial housing for unknown costumers are discussed, and a fully developed fire is recommended as a common requirement for domestic houses, hotels, offices, schools and hospitals.

In addition it is shown how a fire brigade can be expected to perform in a building designed by means of the methodology.

It has been the aim to give a simple and clear presentation and several simplifying concepts are introduced, because it has been experienced that this subject has led to many misunderstandings, and simplicity is needed if the methods presented should be operational.

KEYWORDS: structural fire safety, performance-based requirements, action assessment, concrete structures

\section{NOMENCLATURE LISTING}

$b \quad$ thermal inertia $\left(\mathrm{J} / \mathrm{m}^{2} \mathrm{~s}^{1 / 2} \mathrm{~K}\right)$

$c_{p} \quad$ specific heat $(\mathrm{J} / \mathrm{kgK})$

$F$ force $(\mathrm{kN})$

$O$ opening factor $\left(\mathrm{m}^{1 / 2}\right)$

$q$ fire load $\left(\mathrm{MJ} / \mathrm{m}^{2}\right)$

$T_{f} \quad$ fire temperature $\left({ }^{\circ} \mathrm{C}\right)$

$T_{g} \quad$ gas temperature $\left({ }^{\circ} \mathrm{C}\right)$

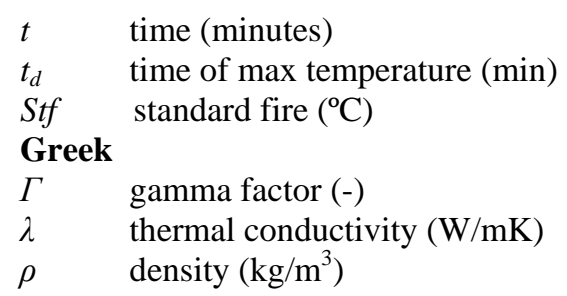

\section{INTRODUCTION}

The Danish architect Arne Jacobsen introduced performance-based design while creating the SAS building 50 years ago (Fig. 1). Instead of describing details of each element in a 
project, he described the performance of the element. This has the great advantage, that details can be changed during the process of design and even during the process of erection without violating the intentions of the design. This new approach was a precondition for the development of industrial housing. Only the fire requirements were not formulated performance-based, because it was too difficult.

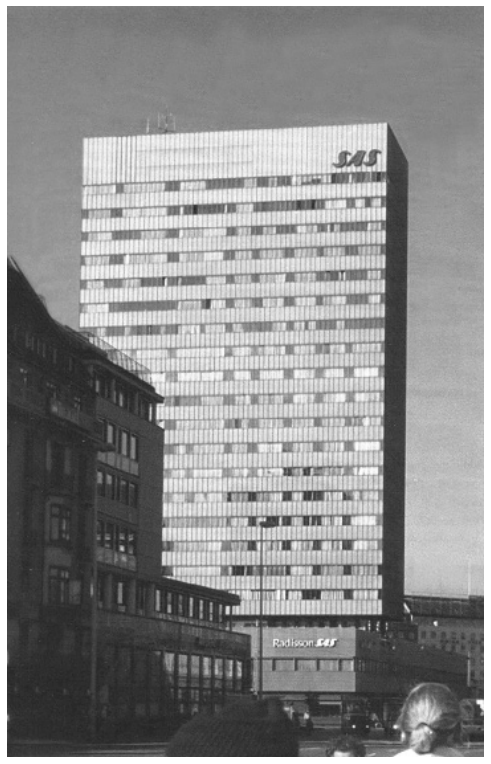

Fig. 1. The SAS building in Copenhagen by Arne Jacobsen.

In the meantime a basis for reliable assessments of fire scenarios has been established, simulation techniques are developed for analyses of evacuation of buildings and methods have been made for design of structures for fully developed fires.

This is the reason why performance-based fire safety design is now introduced in many countries, which means that architects only have to refer to the laws of nature assessing the performance of a building instead of applying fixed sets of prescriptive rules, which have hindered a free design. However, the performance-based design is mostly applied for evacuation and not for the structural design, where traditional requirements in terms of standard fire resistance are still widely used.

One reason for this is lack of knowledge about the methods which are available for designing structures for fully developed fires, but a major reason is uncertainty of how performance-based requirements can be formulated for structures.

The present paper shows how it can be done.

\section{STRUCTURAL RESPONSE}

In order to formulate requirements for structures, it must be considered what is of importance for the structural response.

During 25 years the author has developed a set of methods for the design of any structure of any concrete at any time of any fire Hertz [1-11]. Parts of the methods have been adopted by the Eurocode [12] and the Danish structural codes [13,14]. 
During this work it has become clear that the cooling phase of the fire is very important for the load bearing capacity of a concrete structure. The reason is that it takes time for heat to penetrate a cross section and do any harm to it, and the penetration continues for hours after the fire has been extinguished. A second reason is that calcium hydroxide decomposes into burned limestone and water during a fire, but it reformats in the cooling phase widening up micro cracks and thereby reduces the compressive strength of concrete further $20 \%$ (Hertz [1,9]).

As an example a plain concrete column with a cross section as shown in Fig. 2 can be considered. The column is 4 meter high, centrally loaded and made of a main group concrete according to Hertz [9] with granite aggregate and a compressive strength of $20 \mathrm{MPa}$. It is exposed to a fully developed fire described by an opening factor of $0.04 \mathrm{~m}^{1 / 2}$ and a fire load of $300 \mathrm{MJ} / \mathrm{m}^{2}$ ( $\mathrm{m}^{2}$ enclosing surface), which is similar to a 1 hour standard fire with a cooling phase and relevant for example in a shop in the first floor of a domestic building.
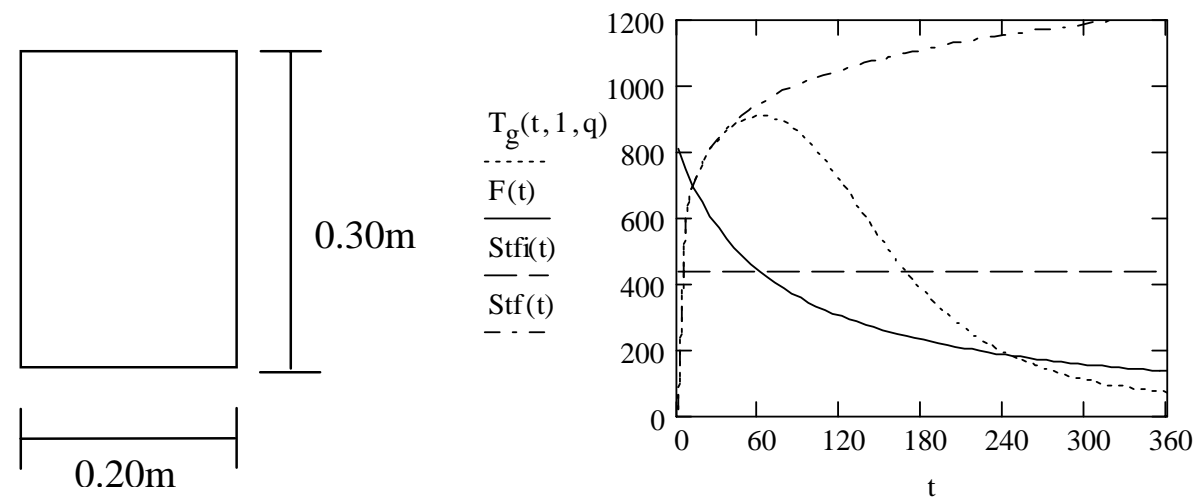

Fig. 2. Cross section of a column and its load bearing capacity $\mathrm{F}(\mathrm{t})$ in $\mathrm{kN}$ in time of a fully developed fire of opening factor $0.04 \mathrm{~m}^{1 / 2}$ and fire load $300 \mathrm{MJ} / \mathrm{m}^{2}$.

Before the fire, this column has a load bearing capacity of $807 \mathrm{kN}$.

After 1 hour, the temperature in the mid point of the cross section is $28^{\circ} \mathrm{C}$, and the concrete here is undamaged. The outer parts of the cross section are somewhat damaged, and the load bearing capacity is $436 \mathrm{kN}$.

After 3 hours, the temperature in the mid point becomes a maximum of $365^{\circ} \mathrm{C}$ and the compressive strength of the concrete here is reduced to $67 \%$ in the cooling phase.

The load bearing capacity of the column reaches a minimum of $228 \mathrm{kN}$.

These results are shown in Fig. 2 in $\mathrm{kN}$ in the same coordinate system as the fire curve in ${ }^{\circ} \mathrm{C}$ (dotted) and the standard fire (dash-dot) versus time in minutes. The dashed curve is the level of the load bearing capacity in $\mathrm{kN}$ after 1 hour standard fire.

The example shows a general picture that many fire exposed compression zones of concrete will have about $50 \%$ of their load bearing capacity left during a fire, which may be reduced to approximately $25 \%$ at the end of the cooling phase. (Large cross sections and heavy reinforcement can make the reduction in the cooling phase less predominant). 
Similar results are often seen for slender concrete columns and beams with slender compression zones such as TT beams and for beams and slabs with fixed end supports, where the compression zones are in the bottom and therefore directly exposed to fire.

It is therefore concluded in Hertz [9], that it is necessary to consider the cooling phase if a design should be made for a fully developed fire, and material properties are given for the hot condition as well as for the cooling phase in the papers Hertz $[8,9,10]$.

This effect is clearly demonstrated in several real fire accidents.

One example is a 12 storey building, which collapsed in Cairo January 27, 2004 with about 15 victims and 45 injured. The building was illegally made like many others in the city, but this is not of importance for the case. What is of importance is, that the building has survived a fire in a shop in the lower storey, and everybody has been evacuated. This means that the building has just proven by the best possible full scale test, that the structure could meet any requirement concerning evacuation time. (Inquiries made by the author in Cairo short after the accident and from a number of news agencies like for example ABC News Online).

The collapse came at a time in the cooling phase, where people reentered the building, and where the heat from the fire penetrated the columns in the lower storey and reduced their load bearing capacity further.

This example and other similar cases confirm a general picture, which the author's design methods indicate, that a design for a limited time of a fully developed fire or a standard fire without cooling is insufficient to show how the load bearing capacity of a structure can develop during a full fire course.

\section{FORMULATION OF FUNCTION-BASED REQUIREMENTS}

If any citizen or politician is asked about the purpose of making a fire safety design, the answer is: To save lives and property.

From the mechanisms described above it is clear that if a qualified structural engineer is asked to design an everyday structure like a concrete column, wall, TT beam etc. to meet a requirement that it should be able to carry its load in a fixed evacuation time, the optimized result can only be a structure, which is doomed to collapse in the cooling phase. If it does not collapse, too much material has been used, and the job has not been done right.

This means that a requirement formulated in terms of evacuation is insufficient for saving property.

Performance-based requirements have been introduced in Denmark by an amendment to the building regulations [15] from June 1, 2004. In these regulations the Danish authorities have taken the extreme attitude that safety of property is entirely a private business. This is done on purpose in order to force the clients and the consultants to formulate their own requirements for the fire safety of property. The building regulations require that evacuation can take place. For the load bearing structures it is said that they should be able to carry their load in the time it takes to evacuate the area of the building, where they are placed. Compartment walls are required to contain the fire in the time it takes to evacuate the compartment and adjacent compartments. 
Even the section walls are allowed to collapse, when people are evacuated from the section. This means that the fire brigade has no chance to extinguish a fire, if it takes more time to do so than the evacuation time, unless supplementary requirements are made for the section walls.

Introducing these radical rules it is clear that the authorities are only concerned about the safety of lives. It has therefore become clearer than ever before that the rules should be considered as minimum requirements, which should be supplemented by requirements formulated by the clients, the consultants, the users and the insurance companies.

\section{DECIDING THE LEVEL OF STRUCTURAL FIRE SAFETY}

From the simple analysis made in this paper it is seen that the first and most important question that a consultant should ask a client concerning the level of fire safety for a structures is:

\section{Do you want a building that collapses?}

If the answer is yes, many consultants including the author would consider refusing to assist the client, unless it is obvious that the building is of minor importance, or the design concerns a part of the building such as a light roof, where a collapse is wanted in order to regulate the fire. The requirement would be that the structure should survive a time necessary for evacuation found by a simulation using relevant fire scenarios for the building. This means that the structure should withstand its load as long as it is needed for evacuation.

If the building is divided in compartments or sections the separating structures should be designed for the time needed to evacuate these and adjacent compartments and sections.

In order to make things clear and operational the author introduces the term Minimum Design for a design meeting this requirement, because it just fulfills the minimum requirements of the society for example as formulated in the Danish Building Regulations [15].

If the answer is no, the most important parts of the structure should be designed to withstand a fully developed fire and compartment separations and section walls can be designed to limit the damages and support the efforts of the fire brigade. The requirement for these walls will be that they should keep their stability, integrity and insulation during the fully developed fire in the building.

In order to assess the fire scenarios used for the design, it might be relevant to ask the client one further question:

\section{Do you rely on the fire brigade?}

To prepare the client for answering this question the consultant must explain that

1) More fires could occur at the same time in the area limiting the efforts, which are possible for the fire brigade to make on the building

2) Fire brigades are paid often by politicians and therefore may be subjected to budget cuts and may have a variable quality in the lifetime of a building.

3) Fire brigades even may be on strike. 
4) Fire brigades may be merged so that the distance to the nearest fire station and the time it takes to come may change.

5) Equipment in the building and systematic education and practice of local people may have an effect on the fire scenarios and could be considered.

6) If the client is a company it could be considered to establish a private fire brigade.

All these considerations are well known, but what is new is that they are made to be used for a structural design.

If the answer is yes, and the consultant and the client agree on the preconditions, reasonable fire scenarios can be developed taking the effect of a fire fighting into account. These will be fully developed fires with cooling phases somewhat earlier than if all combustible material is burned.

The author introduces the term Medium Design for a design meeting this requirement

If the answer is no, or the client just wants the safest possible building, the most important structures are designed for a fully developed fire where all combustible material is burned out.

The author introduces the term Maximum Design for a design meeting this requirement

\section{ASSESSMENT OF DESIGN FIRES}

If a design is made for a particular building and the level of structural fire safety is decided as shown above, a design fire can be derived for each structural element from the fire load, the geometry, openings and thermal properties of the materials in the part of the building. If the element is a part of the enclosure of a compartment or a fire section it is shown that the element can withstand its load and keep its integrity and insulation for a certain time of the fire.

For a minimum design an evacuation time of the fire is used. For a medium design a reduced but fully developed fire course is applied, and for maximum the fully developed fire possible is applied.

For structural design the fire data needed is a temperature-time pulse at the surface of the structure.

The simplest and still most common model describes a temperature-time pulse in the gas in terms of a fire load $q$ in $\mathrm{MJ}$ per $\mathrm{m}^{2}$ surrounding surface and an opening factor $O$ in $\mathrm{m}^{1 / 2}$ and the thermal inertia

$$
b=\sqrt{\rho c_{p} \lambda}\left(J / m^{2} s^{1 / 2} K\right)
$$

where $\rho$ is density, $c_{p}$ specific heat and $\lambda$ thermal conductivity of the boundary.

This gas temperature pulse can then be used directly in structural calculations taking the surface resistance into account or transformed into a surface temperature pulse first.

The fully developed fire can then be described for example using the author's expression in the Danish Action Code [14]. 


$$
\begin{aligned}
& T_{g}=20+\frac{345 \log _{10}(8 \Gamma t+1)}{1+0.04\left(\frac{t}{t_{d}}\right)^{3.5}}\left({ }^{o} \mathrm{C}\right), \text { where } \\
& \Gamma=\frac{\left(\frac{O}{b}\right)^{2}}{\left(\frac{0.04}{1160}\right)^{2}, \quad t_{d}=7.8 \times 10^{-3} \frac{q}{O} \quad \text { (min) }}
\end{aligned}
$$

Many structural design methods for wood, steel and concrete use opening factor and fire load as parameters. If the fire is assessed by other means, the result can be transformed into $q$ and $O$. This can for example be done by plotting a curve for the fully developed fire by means of a spreadsheet, and plot a curve using the expression above in the same coordinate system. Then the two parameters $q$ and $O$ are varied until the two curves fit as shown in Fig. 3. Doing so, the design methods described by $q$ and $O$ can be applied even for places where an opening factor has no meaning. In these cases $q$ and $O$ are just considered as parameters describing a temperature pulse.

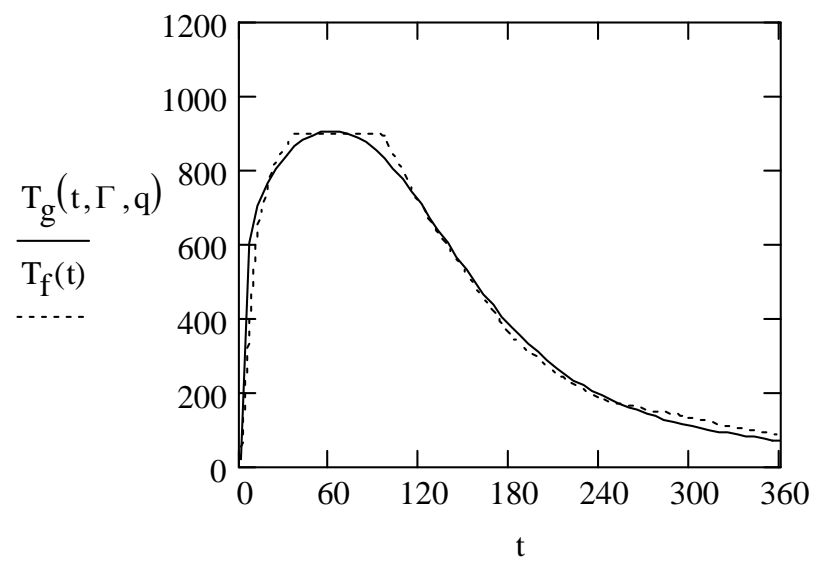

Fig. 3. Assessment of an opening factor curve based on a curve from a two-zone model dotted.

\section{ASSESSMENT OF DESIGN FIRES FOR INDUSTRIAL HOUSING}

Industrial housing is produced in factories, where mostly concrete elements are produced for customers, who are not necessarily known at the time of production. An element factory therefore has to consider which design fires may be relevant for planning the production, and chose some, which can cover as large a span of applications as possible.

The fire loads have been assessed for a great number of cases by means of statistics made in Sweden by Nilsson [16], Berggren and Erikson [17] and Forsberg and Thor [18] prior to the publication of the comprehensive Swedish guide for fire safety design of steel structures Pettersson et al. [19,20].

The statistics show that $80 \%$ of apartments with 3 rooms have a fire load of less than $148 \mathrm{MJ} / \mathrm{m}^{2}$, apartments with 2 rooms $168 \mathrm{MJ} / \mathrm{m}^{2}$, technical offices $140 \mathrm{MJ} / \mathrm{m}^{2}$, schools 
$110 \mathrm{MJ} / \mathrm{m}^{2}$, hospitals $140 \mathrm{MJ} / \mathrm{m}^{2}$ and hotels $80 \mathrm{MJ} / \mathrm{m}^{2}$. Here the units are Mega Joule per square meter enclosing surface.

Based on this information, the author has written a simple rule in the Danish action code [14] that a fire load of $200 \mathrm{MJ} / \mathrm{m}^{2}$ can be used without further documentation for domestic houses, hotels, offices, schools and hospitals.

The thermal inertia $b$ defined above may vary considerably. For producers of light and highly insulated elements of wood, a small value of $b$ should be applied representing the fact that heat produced by a fire in a building with a such construction is hindered to escape from the compartment leading to severe fires with high temperatures.

The situation is the opposite for concrete elements. If a building is made entirely from concrete elements, $b$ can be increased. However, concrete elements are widely used in combination with light elements and brickwork, and it is therefore recommended to apply $b=1150 \mathrm{~J} / \mathrm{m}^{2} \mathrm{~s}^{1 / 2} \mathrm{~K}$ representing a standard fire compartment, if the costumer is not known beforehand.

The opening factor varies with the geometry applied. For some light not insulated elements a high opening factor will be most severe, because these structures are susceptible to high gas temperatures. But for heavy elements, a low opening factor is most dangerous, because for these structures a long time of exposure is crucial.

In order to find a reasonable design fire for concrete elements, the following analyses can be made, which clearly show the effect.

In Table 1, the results are presented for a calculation of the maximum temperature, which will occur in a reinforcing bar in a fire-exposed slab with a typical cover thickness of $30 \mathrm{~mm}$ to the centre line of the bar. The table also presents the average reduction of the compressive strength in a compression zone of width $150 \mathrm{~mm}$ exposed to fire on both sides. Finally the table shows the load bearing capacity of the $4 \mathrm{~m}$ column mentioned at the beginning of this paper.

The authors simplified calculation methods are applied for example as found in CEN [12] Annex B2 and in DS [13], Hertz [5] and Hertz [3]. The reduction is given for a main group concrete according to Hertz [9] for a hot condition during a fire, where the reinforcement is the weakest and for a cold condition at the end of the cooling phase, where the concrete is the weakest.

The calculation is made for a selection of fully developed fires with fire load $200 \mathrm{MJ} / \mathrm{m}^{2}$ enclosing surface and opening factors from $0.02 \mathrm{~m}^{1 / 2}$ to $0.12 \mathrm{~m}^{1 / 2}$ and the thermal inertia of a standard compartment.

The table also shows the same values for a standard fire of 60 and 120 minutes and for the same standard fires, if a cooling phase was included, i.e. if the specimen was not unloaded at the maximum gas temperature. This cooling phase is included as an option in the test standard ISO 834, but is almost never applied.

Finally the calculation is made for the fully developed fire of opening factor $0.04 \mathrm{~m}^{1 / 2}$ and fire load $300 \mathrm{MJ} / \mathrm{m}^{2}$, which was applied for the column example previous in this paper, and it is seen that this gives nearly the same results as the 60 minutes standard fire with cooling. 
Table 1. Influence of design fires on the maximum temperature of a reinforcing bar, the strength reduction of a concrete compression zone and of a column.

\begin{tabular}{|c|c|c|c|c|c|c|}
\hline \multirow[t]{2}{*}{ Fire course } & \multirow[t]{2}{*}{$\begin{array}{c}\begin{array}{c}\text { Opening } \\
\text { factor }\end{array} \\
\mathrm{m}^{1 / 2}\end{array}$} & \multirow[t]{2}{*}{$\begin{array}{c}T_{\max } \\
\text { in slab } \\
\text { with } \\
30 \mathrm{~mm} \\
\text { cover } \\
{ }^{\circ} \mathrm{C} \\
\end{array}$} & \multicolumn{2}{|c|}{$\begin{array}{c}\text { Reduction of } \\
\text { concrete } \\
\text { strength } \\
150 \mathrm{~mm} \\
\text { section }\end{array}$} & \multicolumn{2}{|c|}{$\begin{array}{c}\begin{array}{c}\text { Reduction } \\
\text { of column } \\
\text { strength }\end{array} \\
200 \times 300 \times 4000\end{array}$} \\
\hline & & & Hot & Cold & Hot & Cold \\
\hline $200 \mathrm{MJ} / \mathrm{m}^{2}$ & 0,02 & 448 & 0.75 & 0.43 & 0.61 & 0.33 \\
\hline $200 \mathrm{MJ} / \mathrm{m}^{2}$ & 0,04 & 418 & 0.81 & 0.53 & 0.63 & 0.38 \\
\hline $200 \mathrm{MJ} / \mathrm{m}^{2}$ & 0,08 & 376 & 0.83 & 0.63 & 0.64 & 0.40 \\
\hline $200 \mathrm{MJ} / \mathrm{m}^{2}$ & 0,12 & 325 & 0.84 & 0.67 & 0.65 & 0.44 \\
\hline $300 \mathrm{MJ} / \mathrm{m}^{2}$ & 0,04 & 484 & 0.73 & 0.40 & 0.53 & 0.29 \\
\hline 60 minutes Standard Fire & $(0,04)$ & 413 & 0.81 & - & 0.54 & - \\
\hline 60 minutes St. Fire with cooling & $(0,04)$ & 488 & 0.70 & 0.37 & 0.52 & 0.28 \\
\hline 120 minutes Standard Fire & $(0,04)$ & 589 & 0.56 & - & 0.33 & - \\
\hline 120 minutes St. Fire with cooling & $(0,04)$ & 644 & 0.36 & 0.00 & 0.26 & 0.04 \\
\hline
\end{tabular}

The results in Table 1 demonstrate that the smallest opening factor is most severe for a concrete structure because time is more dominant than gas temperature for the destruction.

The author therefore recommends that concrete element factories apply the design fire given by an opening factor of $0.02 \mathrm{~m}^{1 / 2}$ and fire load $200 \mathrm{MJ} / \mathrm{m}^{2}$ enclosing surface for a production of elements intended for domestic houses, hotels, offices, schools and hospitals. This group covers a large part of the production for industrial housing. If the factory also produces elements for the industry, the design program needs to be supplemented with some special variants of improved fire resistance for shops, industrial factories and other applications with large fire loads.

It is seen, that even though the fire load is reduced compared to a standard fire, this recommended fully developed design fire is more severe for all tree examples than a 1 hour standard fire without cooling.

\section{CONSEQUENCES FOR THE FIRE BRIGADE}

In countries like Denmark where performance-based fire safety design is introduced, the analyses above show that it may have severe consequences for the work of the fire brigade.

1) If a minimum design is chosen, or the fire brigade does not know whether a minimum design is chosen or not, this means that the building and its section walls do not support fire fighting more than the time of an evacuation. In a building like this, the fire brigade is therefore supposed to assist the evacuation, abandon the building and bar the site so that nobody is let in, before the structure is analyzed, and it is decided whether the building should be reused or demolished.

2) If the fire brigade positively knows that a maximum design is made, efforts can be spent to extinguish the fire and save as much as possible. 
3) If the building is known to meet a medium design, it must be up to the fire brigade to estimate whether they have arrived on time and the fire seems to be as foreseen. If this estimation is positive, 2) may apply otherwise 1).

A fire brigade therefore needs to know the safety level of the structural design of every building in the district, because this can seldom be seen from the appearance of the structures. Alternatively every building could have a mark - for example a smiley on the entrance door showing the structural fire safety level in terms of mini, midi or maxi. This would also pass the information to the users of the building.

\section{CONCLUSIONS}

It is shown that the load bearing capacity of structural elements may be almost halved in a hot condition during a fire and almost halved once again in the cooling phase and that the cooling phase therefore is very important for the stability of a structure during a fully developed fire course. The cooling phase is therefore important for the assessment of function-based requirements for a structure. It is shown that the minimum requirements found in many national building regulations need to be supplemented if safety of property is considered to be of importance. A methodology and a simple set of concepts is developed by means of which a consulting engineer can guide a client through a process, where the structural safety level can be decided. It is shown how design fires can be assessed in detail from the decisions of the safety level, and what is needed to be required for the structure.

Finally it is shown that a fully developed fire with an opening factor of $0.02 \mathrm{~m}^{1 / 2}$ and a fire load of $200 \mathrm{MJ} / \mathrm{m}^{2}$ enclosing surface is a sufficient fire safety requirement for a production of concrete elements intended to be used in domestic houses, hotels, offices, schools and hospitals.

\section{REFERENCES}

[1] Hertz, K.D., "Betonkonstruktioners brandtekniske egenskaber,” (Fire Properties of Concrete Constructions) Part 1 of Ph.D. - Thesis, Report Nr.140, Institute of Building Design, Now: Department of Civil Engineering, Technical University of Denmark, Lyngby, 1980, 210 p.

[2] Hertz, K.D., "Reference List on Concrete Constructions Exposed to High Temperatures,” Part 3 of Ph.D. - Thesis, Report No.141, Institute of Building Design, Now: Department of Civil Engineering, Technical University of Denmark, Lyngby, 1980, 63 p.

[3] Hertz, K.D., "Simple Temperature Calculations of Fire Exposed Concrete Constructions," Report No.159, Institute of Building Design, Technical University of Denmark, Lyngby, 1981, 54 p, CIB W14/81/13 (DK).

[4] Hertz, K.D., "The Anchorage Capacity of Reinforcing Bars at Normal and High Temperatures,” Magazine of Concrete Research, 34(121):213-220 (1982), December.

[5] Hertz, K.D., “Analyses of Prestressed Concrete Structures Exposed to Fire,” Report 174, Institute of Building Design now: Department of Civil Engineering, Technical University of Denmark, Lyngby, 1985, 152 p. CIBW14/88/49(DK), CIB Conference in Kyoto, June 1988. 
[6] Hertz, K., "Documentation for Calculations of standard Fire Resistance of Slabs and Walls of Concrete with Expanded Clay Aggregate," Report No. R-048 Department of Civil Engineering, Technical University of Denmark, December 2002, 43 p.

[7] Hertz, K.D., “Limits of Spalling of Fire-Exposed Concrete,” Fire Safety Journal, 38:103-116 (2003).

[8] Hertz, K.D., "Reinforcement Data for Fire Safety Design," Magazine of Concrete Research, 56(8):453-459 (2004), October.

[9] Hertz, K.D., “Concrete Strength for Fire Safety Design,” Paper accepted for publication by Magazine of Concrete Research, November 2004, 17 p.

[10] Hertz, K.D., “Quenched Reinforcement Exposed to Fire,” Paper accepted for publication by Magazine of Concrete Research, March 2005, 10 p.

[11] Hertz, K.D. Sørensen, L.S., “Test Method for Spalling of Fire Exposed Concrete,” Paper accepted for publication by Fire Safety Journal, FISJ1473, Arpil 2005, 8 p.

[12] CEN ENV, 1992-1-2, Design of Concrete Structures; General Rules, Structural Fire Design, CEN Management Centre, Brussels 1994 and March 2004.

[13] DS, Danish Code of Practice for Concrete Constructions, DS411, Version 4.1, Danish Standardisation Organisation, 1999.

[14] DS: Danish Code of Practice for Actions, DS410, Version 4.1, Danish Standardisation Organisation, 1999.

[15] NAEC, Danish Building Regulations Amendment 8, National Agency for Enterprise and Construction, June 2004.

[16] Nilsson, L., "Brandbelastning i bostadslägenheter,” Statens Institut för Byggnadsforskning, Rapport R34, 1970, Dtockholm 1970.

[17] Berggren, K. and Erikson, U., "Brandbelastning i kontorhus. Statistisk inventering och utvärdering,” Stålbyggnadsinstitutet, Rapport 18:1, Stockholm 1970.

[18] Forsberg, U. and Thor, J., "Brandbelastningsstatistik för skolor och hotell," Stålbygnadsinstitutet, Rapport 44:1, Stockholm 1971.

[19] Pettersson, O., Magnusson, S.E., and Thor, J., ”Brandteknisk dimensionering av stålkonstruktioner," (Swedish edition of [20]), Publikation 38, Stålbyggnadsinstitutet, Stockholm 1974.

[20] Pettersson, O., Magnusson, S.E., and Thor, J., "Fire Engineering Design of Steel Structures,” (English edition of [19]), Bulletin 52, Publication 50, Swedish Institute of Steel Construction, Stockholm 1976. 
